Article

\title{
Embedding Behavior of Ceramic Particles in Babbitt Coatings and Its Effect on the Tribological Properties of Low-Pressure Cold Sprayed Coatings
}

\author{
Wolfgang Tillmann, Mohamed Abdulgader *, Leif Hagen and Steffen Hüning \\ TU Dortmund, Institute of Materials Engineering, 44227 Dortmund, Germany; \\ wolfgang.tillmann@tu-dortmund.de (W.T.); leif.hagen@tu-dortmund.de (L.H.); \\ steffen.huening@tu-dortmund.de (S.H.) \\ * Correspondence: mohamed.abdulgader@udo.edu
}

Received: 31 May 2020; Accepted: 4 August 2020; Published: 7 August 2020

\begin{abstract}
The low melting point of Sn-based Babbitt alloys often causes nozzle clogging in the low-pressure cold gas-dynamic spraying (LPCGDS) process, which impacts the process steadiness and the coating quality. Adding hard particles to the feedstock material eliminates this kind of interruption. A certain amount of these particles finds their way in the obtained coatings. These particles also trigger a kind of "hammering effect" due to their impulse forces. These forces are directly dependent on the mass and velocity of the impacting hard particles. However, these forces may lead to a decrease in the porosity and improve the adhesion of the obtained coating. In this study, the effect of the density and size of the hard particle was examined by three different hard materials, $\mathrm{Cr}_{3} \mathrm{C}_{2}, \mathrm{Al}_{2} \mathrm{O}_{3}$, and $\mathrm{B}_{4} \mathrm{C}$, which have a material density of $6.68,3.95$, and $2.52 \mathrm{~g} / \mathrm{cm}^{3}$, respectively. The used feedstock in this study is a powder mixture that contains $75 \mathrm{vol} \%$ Babbitt and $25 \mathrm{vol} . \%$ of either $\mathrm{B}_{4} \mathrm{C}, \mathrm{Cr}_{3} \mathrm{C}_{2}$, or $\mathrm{Al}_{2} \mathrm{O}_{3}$. The effect of the size distributions "particles with lower mass" was tested using two different $\mathrm{Al}_{2} \mathrm{O}_{3}$. The various hard particles show different embedding behaviors, as well as different effects on the coating build-up. It was found that the blended hard particles were enclosed with the Babbitt matrix, and their interface with Babbitt shows no clear evidence of pronounced diffusion. The size distribution of the blended hard particles has a direct effect on the splat formation and the obtained coating microstructure. It was found that the type of hard particles played a decisive role in the friction behavior. Nevertheless, the hard particle reinforced Sn-Sb-Cu-based composite coatings demonstrated a nearly constant coefficient of friction throughout the load-interval.
\end{abstract}

Keywords: Low-Pressure Cold Gas-Dynamic Spraying (LPCGDS) process; Sn-based Babbitt coatings; tribological behavior; embedding of hard particles; particle size distribution; splat formation

\section{Introduction}

Metal deposition processes are mostly referred to as thermal spraying processes, which make use of the combination of thermal and kinetic energies to heat-up feedstock materials (metals or composite of metals and metal-ceramics) and accelerate them towards a prepared substrate surface. However, the ratio between thermal and kinetic energies in the thermal spraying processes determines the impulse (linear momentum) of the impacting particles, and thus their spreading behavior upon the prepared substrate surface. One of the main factors that control the impulse forces of the inflight particles is their mass. Changing the mass of the inflight particles by either changing their density or size will affect their impulse forces directly. Another way of changing the impulse forces of the in-flight particles upon impacting is to change their temperature, which changes the density of the in-flight particles, and if the temperature high enough, even their state of matter. 
The higher process temperatures in high-velocity oxygen fuel (HVOF), atmospheric plasma spraying (APS), and twin wire arc spraying (TWAS) may lead to phase transformations. These changes may introduce undesirable features like the increase in both brittleness of the hard materials and amorphousness of the metal binder [1,2]. Adding nitrogen to the HVOF flame decreases the flame temperature, and thus suppresses the decarburization of hard materials [3,4]. A further decrease in the process temperature (lower than $600^{\circ} \mathrm{C}$ ) makes it possible to avoid the defects mentioned above.

In the last two decades, a new spraying technique called cold gas-dynamic spray (CGDS) has gained more and more in importance. Heating and accelerating compressed gases (air, nitrogen, or helium) is the main concept behind this technique. It allows for depositing mainly metals and, more recently, also metal matrix composite (MMC) powders as a feedstock material. An important issue, thereby, is that the obtained particle velocity and thus the exerted impulse forces should exceed a critical value, which is dependent on the combination of spraying and substrate material. The impulse forces allow for the bonding of particles to the substrate (coating adhesion) as well as the coating build-up (coating cohesion). They may lead to localized plastic deformation of the impacting particles that determine both coating adhesion and cohesion [5-8]. The impulse forces are considered, therefore, as the primary mechanism for the coating build-up, and the obtained adherence. Therefore, the specific weight and the obtained in-flight particle velocity are essential factors in determining whether a coating build-up or erosion occurs [5]. Champagne et al. [5] found that the coating deposition in cold spray involves two different stages. The interface between the substrate surface and the first layer is considered as the first stage. The second stage starts with the deposition of the spray particles on the top of the previous layers. Each of these stages has its own requirement on the critical velocity of the impacting particles. It is a common practice that the feedstock materials differ from the substrate material, which requires the reconsideration of the critical velocity in the above-described stages. Changing the impact velocities is necessary to achieve a coating with the adhesion of coating needed as well as the desired coating microstructure [5]. However, the feedstock in the CGDS remains, in most cases, in its unmelted state during the entire deposition process, which means that almost no phase changes will take place.

Two different types of cold gas-dynamic spraying (CGDS) techniques were introduced to the spraying market. Regarding the gas pressure, the CGDS is divided into high pressure cold gas-dynamic spray (HPCGDS) and low pressure cold gas-dynamic spray (LPCGDS), which is high (>1 MPa) and low ( $<1 \mathrm{MPa})$ pressure cold gas-dynamic spray, respectively. Figure 1 shows schematic overviews of both process categories. Another distinguishing feature between both process categories is the powder feeding system. While the powders in the LPCGDS process are drawn from the powder feeder by the Venturi effect [6], it requires a separate powder feeding unit in the case of the HPCGDS process. The relatively low pressure and simple powder feeding system make LPCGDS the cheapest alternative and capable of depositing powder particles between up to $50 \mu \mathrm{m}$ at low temperatures up to $600^{\circ} \mathrm{C}$ to different substrate materials [7-10]. Furthermore, most of the commercial LPCGDS systems offer, besides their compact dimensions and low cost, high modifiability $[5,10]$.

In the literature, different opinions were expressed about the extent of the amount of the individual energy (thermal and kinetic) and their effect on the obtained coating microstructure [11-13]. Yin et al. [11] asserted the opinion that the increase in gas temperature has a higher impact on the obtained microstructure than increasing gas pressure. Assadi et al. [12] and Rakoni et al. [13] both concluded that higher particle impact velocity results in improved deposit properties. They added that the increase in particle impact velocity improves both the deposition efficiency and adhesion strength significantly $[12,13]$. Moreover, the impact velocity also leads to a rise in the deposit hardness owing to the enhanced work-hardening effect [14,15]. The high internal stresses affected the adhesion strength of cold spray coatings as the coating thickness increased [5-7,10]. Micro-pores and inter-particle boundaries are the common defects that are found in CGDS deposited coatings. At low velocity, the impacting particles exhibit insufficient plastic deformations, and thus weak inter-particle bonding $[7,14,15]$. These defects can impair the performance of the obtained coatings. 
a) High pressure cold gas-

dynamic spray process

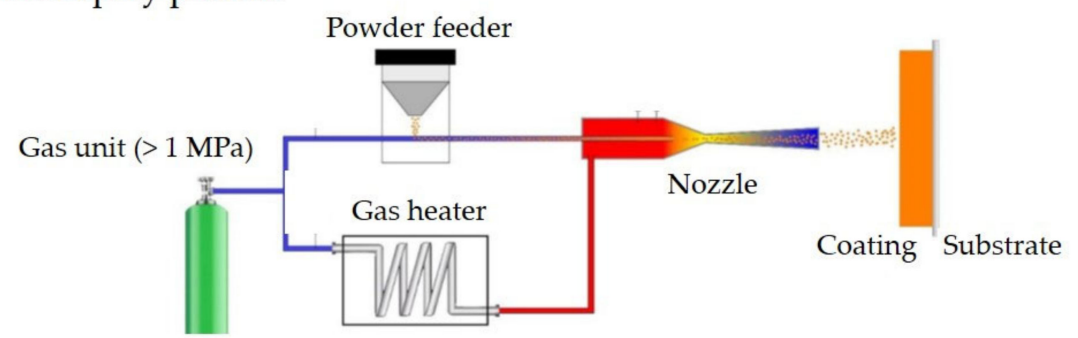

b) Low pressure cold gas-

dynamic spray process

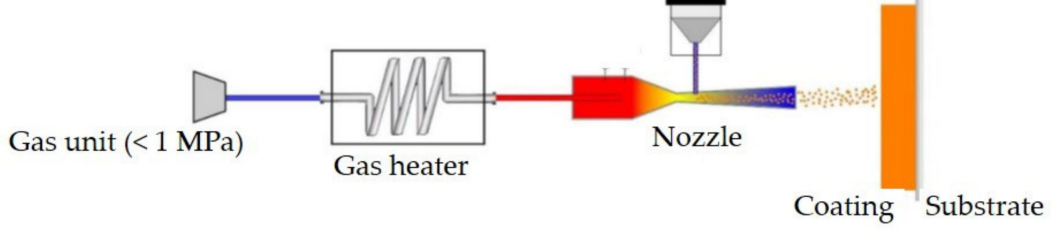

Figure 1. Schematic representation of the various cold gas-dynamic spray processes: (a) high pressure cold gas-dynamic spray process (HPCGDS), (b) low pressure cold gas-dynamic spray process (LPCGDS) [5].

Ganesan et al. [7] found that the low yield strength of the feedstock material directly affects the deposition efficiency. They observed that tin feedstock powder showed a higher deposition efficiency compared with copper powder. While Ganesan et al. [7] deposited electrical conductive copper coatings successfully on a polyvinyl chloride (PVC) substrate, and in Małachowska et al. [9], pure aluminum and tin were deposited onto the polycarbonate substrate. Melendez et al. [16] used the LPCGDS to deposit sintered and crushed tungsten carbide WC-based powders. The WC-powder was mechanically blended with nickel powder and used to produce various MMC coatings. The inclusion of WC and the free path between these particles increased the strength and improved the mechanical properties of the obtained coating. The resulting porosity has been reduced with the increase of the WC content in the feedstock powder. The decrease in porosity was the result of the work-hardening of the impacting harder WC particles onto the coating. The low process temperature and the short in-flight time of the spray particles eliminate any phase transformations [16]. It was found that the ceramic particles enhance through the development of in situ craters the coating build-up [17,18]. The volume fraction and mass (material density and powder size) of the blended (mixed in) hard particles have not yet been sufficiently researched.Depositing Sn-based Babbitt as a plain bearing material using LPCGDS is a very promising field of application. Despite its relatively higher cost, Sn-based Babbitt alloys reveal a low hardness, abrasion resistance to steel, low stiffness, excellent corrosion resistance, good embedding ability of foreign particles, less tendency towards segregation, and last but not least low coefficient of friction [19-21]. Therefore, Babbitt as an alloy is mainly used as a sliding layer in plain hydrodynamic bearings to reduce friction [19]. Babbitt, in general, consists mostly of the elements tin (Sn), copper $(\mathrm{Cu})$, and antimony $(\mathrm{Sb})$. Tin, as the main component of the alloy, acts, in the case where no lubricant is available, as a solid lubricant with low hardness, and thus functions as a sacrificial surface [20]. Depending on the amount of the individual constituents, Babbitt can be classified according to ASTM B-23 into different grades. Spraying ductile and low melting materials using the LPCGDS, like the Sn-based Babbitt, is a challenging task and usually leads to clogging of the spray nozzle. Mixing Babbitt with hard particles like alumina $\mathrm{Al}_{2} \mathrm{O}_{3}$ particles is, therefore, a common praxis to avoid clogging of the spray nozzle and allowing for the deposition of such materials. 
This work aims to study the effect of material density and size of the required hard materials on the coating build-up, splat formation, embedding, and friction behavior of the obtained Sn-based Babbitt coating. Investigating the embedding behavior of the different hard particles in the Sn-based Babbitt metallic matrix is essential for coating development. In order to understand the effect of the material density and the size of the hard particles on the coating build-up, splat analyses were conducted for all powder mixtures. The density and size of the mixed-in hard particles determine their velocity at impact, and, therefore, the obtained impulse forces exerted upon the substrate surface or previously deposited layers. Furthermore, the friction and wear results of the obtained coating in this work are compared with those of conventional Sn-Babbitt bearing surfaces with a similar chemical composition that were investigated by Ji et al. [22].

\section{Materials and Methods}

The bearing metal Sn-Babbitt Grade 3 was blended according to the standard ASTM-B23 to the following composition of $84.0 \mathrm{wt} . \%$ of $\mathrm{Sn}, 8.0 \mathrm{wt} . \%$ of Sb, and $8.0 \mathrm{wt} . \%$ of $\mathrm{Cu}$. The Sn-Babbitt Grade 3 was then mixed with three different hard particle materials $\left(\mathrm{Al}_{2} \mathrm{O}_{3} ; \mathrm{B}_{4} \mathrm{C}\right.$ (TETRABOR Borncarbid F180 $(-90+52 \mu \mathrm{m}), 3 \mathrm{M}-\mathrm{GmbH}$ Neus, Germany), $\mathrm{Cr}_{3} \mathrm{C}_{2}$ (AMPERIT850 $(-90+45 \mu \mathrm{m})$ Höganäs $\mathrm{AB}$, Höganäs, Sweden)), using a volumetric ratio of 75:25. These hard materials have almost the same powder size distribution as well as the same shape, but possess different material density. While $\mathrm{B}_{4} \mathrm{C}$ shows, with $2.52 \mathrm{~g} / \mathrm{cm}^{3}$, the lowest density among all other hard materials used, $\mathrm{Cr}_{3} \mathrm{C}_{2}$ possesses the highest density of $6.62 \mathrm{~g} / \mathrm{cm}^{3}$, with a density of 3.95 leis $\mathrm{Al}_{2} \mathrm{O}_{3}$ in between. The effect of the size distribution of the hard particles was explored using two different size distribution with identical density and shape. $\mathrm{Al}_{2} \mathrm{O}_{3}$ was used for this part of this study owing to its density. The two powders were METCO 6103 $(-45+15 \mu \mathrm{m})$, Oerlikon Metco Ltd., Wohlen, Switzerland, and the Amperit $740.002(-90+45 \mu \mathrm{m})$, H.C. Stark, Goslar, Germany. The four blended feedstock powders were sprayed utilizing a portable DYMET 413 LPCGDS spraying system (Fa. Dycomet, Akkrum, Netherlands). Industrial robot system type IRB 4600 (ABB Ltd., Baden, Switzerland) was used to allow for uniform coating thickness and equal thermal load on the substrate and, at the same time, to execute the splat experiments. Table 1 shows the optimal spray parameters, which are capable of producing coatings with low porosity, high homogeneity, and a smooth surface.

Table 1. Spray parameters.

\begin{tabular}{cc}
\hline Parameters & Value \\
\hline Gas temperature $\left[{ }^{\circ} \mathrm{C}\right]$ & 400 \\
Gas pressure $[\mathrm{bar}]$ & 5.0 \\
Powder feed rate $[\mathrm{g} / \mathrm{s}]$ & $0.50-0.60$ \\
Stand-off distance $[\mathrm{mm}]$ & 10 \\
Spray angle $\left[{ }^{\circ}\right]$ & 90 \\
Transverse speed $[\mathrm{mm} / \mathrm{min}]$ & 6000 \\
Overruns [passes] & 6 \\
\hline
\end{tabular}

Figure 2 shows the beam shutter that is used to collect splats from each experimental run of the different feedstock powders. The robot was so programmed that the spray gun was directly positioned in the front of the splat device for $20 \mathrm{~s}$. After the falling shield unit has moved to its end-position and the splats are collected, the coating of the nearby in a separate fixture mounted substrate begins immediately. 


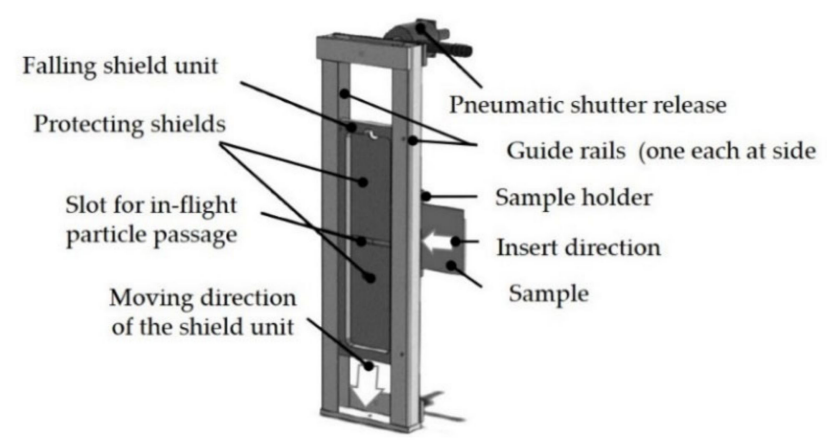

Figure 2. Beam shutter for splat investigation through a short-time exposure of a static spray gun.

Cylindrical specimens made of 1.0503 steel (ø $40 \mathrm{~mm}$ and $6 \mathrm{~mm}$ thickness) were used for the splats and coating experiments. In the case of splat investigation, the substrate surface was polished to mirror finish $(R a=0.08 \mu \mathrm{m} \pm 0.02)$. The substrate surface was sandblasted with corundum $(-150+106 \mu \mathrm{m})$ using compressed air at a pressure of $0.4 \mathrm{MPa}$, a stand-off distance of $100 \mathrm{~mm}$, and a blasting angle of approximately $45^{\circ}$. The sandblasted specimens were roughened to $\mathrm{Ra}=9.4 \mu \mathrm{m}( \pm 1.2 \mu \mathrm{m})$, and were then placed in an ultrasonic ethanol bath to remove oil residues and foreign particle inclusions.

The obtained splats and coatings were characterized using the energy-dispersive X-ray spectroscopy (EDS) of a field emission scanning electron microscope (FE-SEM) (type JSM-7001F, Jeol, Freising, Germany). This microscope is equipped with secondary electrons (SE), backscattered electrons (BSE), as well as energy-dispersive X-ray detectors (Oxford Instruments, Abingdon, UK). The data were analyzed with the EDS microanalysis software INCA (Oxford Instruments, Abingdon, UK). A ball-on-disk (BOD) tribometer (CSM Instruments, Peuseux, Switzerland) was used to perform the tribological tests on the coatings. The sliding tests were carried out at room temperature without lubricants using a 100Cr6 ball with a $6 \mathrm{~mm}$ diameter as a counter body. The velocity and the load were kept constant at $0.4 \mathrm{~m} / \mathrm{s}$ and $5 \mathrm{~N}$, respectively. A total number of 10,000 revolutions were conducted on a constant radius, which corresponds to a sliding distance of $950 \mathrm{~m}$. The coefficient of friction (COF) was determined via measurements of the tangential force and the applied normal force. The topography of the obtained splats was measured by 3D-profilometry (LEICA DVM6, Leica Mikrosysteme GmbH, Wetzlar, Germany).

\section{Results}

This work focused on the effect of the density and size of hard particles on splat formation, coating build-up, and embedding behavior of remaining hard particles. Figure 3 shows the microstructure of powders that were used for this study. It also shows the microstructure of the blended mixture of Babbitt and $\mathrm{Al}_{2} \mathrm{O}_{3}$. The Babbitt powder shows an inhomogeneous structure of large and spherical tin particles, small and angular shaped antimony, and dendritic Copper particles.

Chromium(II) carbide has among all other hard particles the highest density of $6.68 \mathrm{~g} / \mathrm{cm}^{3}$ compared with $3.94 \mathrm{~g} / \mathrm{cm}^{3}$ in the case of aluminum oxide, and $2.51 \mathrm{~g} / \mathrm{cm}^{3}$ for boron carbide. On the contrary, Chromium(II) carbide has the lowest melting temperature of $1895^{\circ} \mathrm{C}$ compared with aluminum oxide and boron carbide of 2050 and $2350{ }^{\circ} \mathrm{C}$, respectively. The coating shown in Figure $3 \mathrm{e}$ was made from Babbitt, and $\mathrm{Al}_{2} \mathrm{O}_{3}$ METCO $6103(-45+15 \mu \mathrm{m})$. The images of this coating show an excellent interface between the Babbitt coating and the substrate material, which indicates a higher adhesion strength of the obtained coating. The coating adhesion for both sizes of the hard particle powders $\left(\mathrm{Al}_{2} \mathrm{O}_{3}\right)$, compared with other thermal spraying techniques, is low. However, it is much higher in the case of finer $(-45+15 \mu \mathrm{m}) \mathrm{Al}_{2} \mathrm{O}_{3}$ particles (about $\left.8.5 \mathrm{MPa} \pm 0.6\right)$ compared with $(2.6 \mathrm{MPa}$ $\pm 0.3)$ in the case of coarse $(-90+52 \mu \mathrm{m}) \mathrm{Al}_{2} \mathrm{O}_{3}$ particles. The hardness of the obtained coatings ranges between $18.55 \mathrm{HV} 0.05 \pm$ for $\mathrm{Cr}_{3} \mathrm{C}_{2}, 24.0 \mathrm{HV} 0.05 \pm 1.7$ for $\mathrm{B}_{4} \mathrm{C}$, and $26.21 \mathrm{HV} 0.05 \pm 3.9$ for $\mathrm{Al}_{2} \mathrm{O}_{3}$. In the case of the finer $\mathrm{Al}_{2} \mathrm{O}_{3}$, the obtained hardness is higher and is about $33.95 \mathrm{HV} 0.01 \pm 3.78$. 

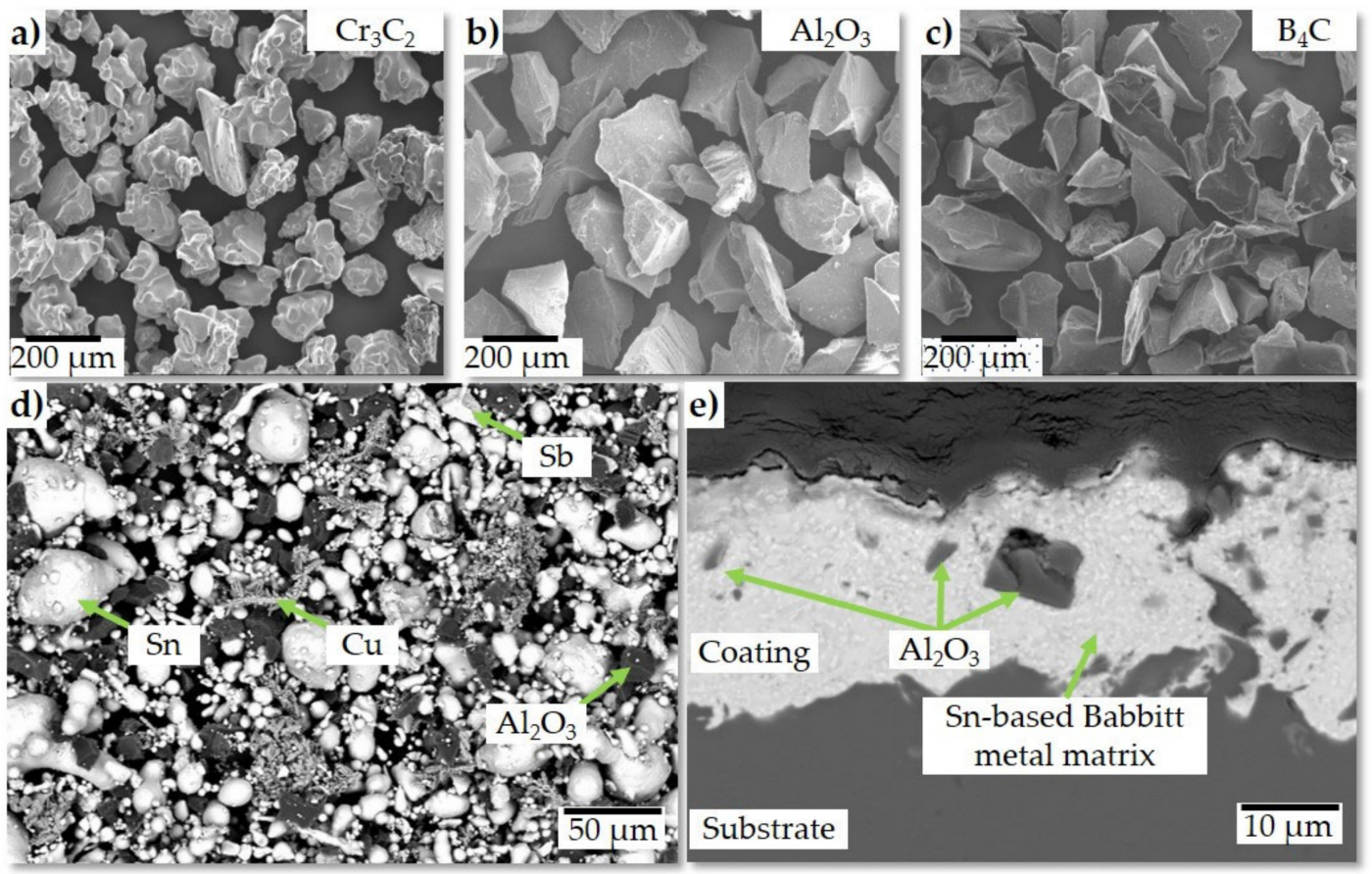

Figure 3. Scanning electron microscopic (SEM) images of the hard particle powders, blended powder, and the obtained coating: (a) $\mathrm{Cr}_{3} \mathrm{C}_{2}$, (b) $\mathrm{Al}_{2} \mathrm{O}_{3}$, and (c) $\mathrm{B}_{4} \mathrm{C}$; (d) blended Sn-based Babbitt with $\mathrm{Al}_{2} \mathrm{O}_{3}$;

(e) Babbitt $/ \mathrm{Al}_{2} \mathrm{O}_{3}$ coating.

\subsection{Splat Analyses}

Splats are the individual building blocks for any thermal sprayed coating and control the obtained coating microstructure. The impacting particles in thermal spraying processes, where the temperature of the in-flight particles are close or even over the melting point of the feedstock materials, generate splats with different shapes. In the case of LPCGDS, the feedstock material, and in particular, the mixed-in hard particles, remain in their solid-state. The ductile part of the feedstock becomes softened through the gas temperature and, therefore, deforms after impacting in hilly terrain and pile up, as shown in Figure 4. The accumulated materials do not include any traces of the hard particles, as can be seen in Figure 4b. A low deformation work was done upon the impacting in-flight particles. The obtained spalts are characterized by no definite shape, texture, and profile integrity.
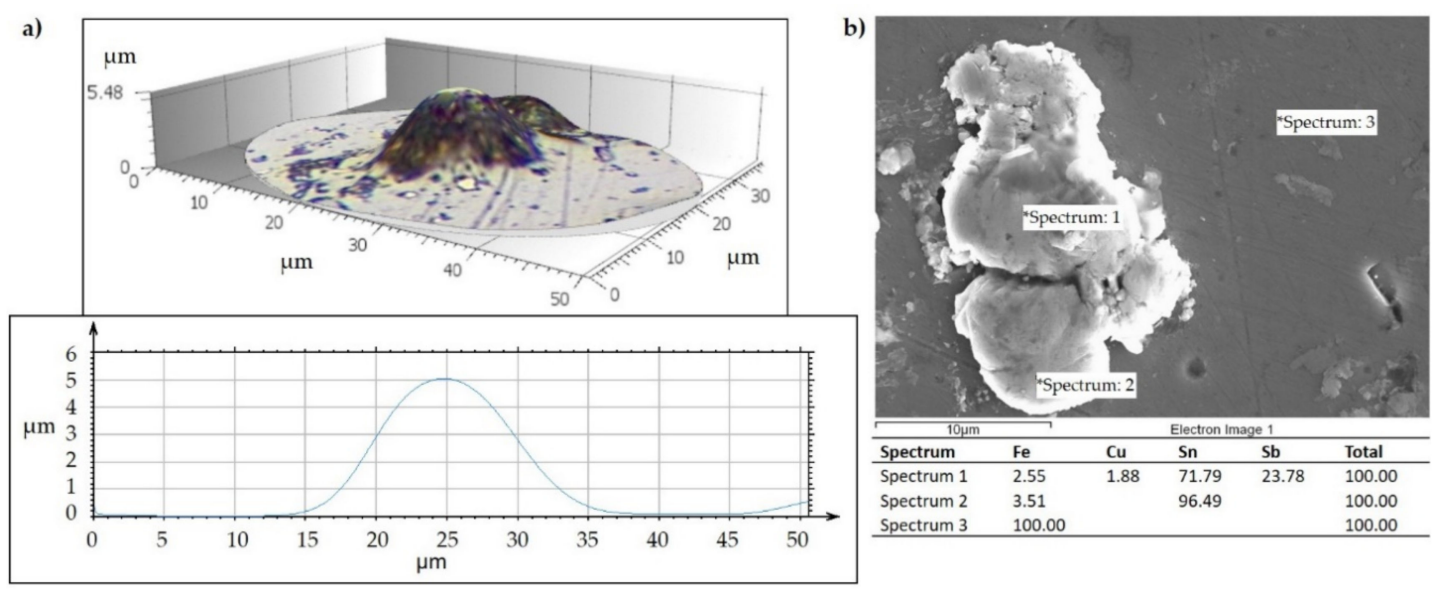

Figure 4. Images of the obtained splats mainly from Sn-Babbitt material: (a) 3D-pattern of a splat, (b) scanning electron microscopic (SEM) image and the composition of a splat. 
Even though the percentage of copper and antimony is equal in the Babbitt feedstock powder, the percentage of copper in the obtained splat is negligible compared with the other constituents. The splats of all four blended feedstock mixtures possess the same shape and contain mainly tin. As the hard particles bounce off the substrate surface, it creates a crater. The size and depth of the crater are directly dependent on the size distribution and the material density of the mixed-in hard particles, as shown in Figure 5.

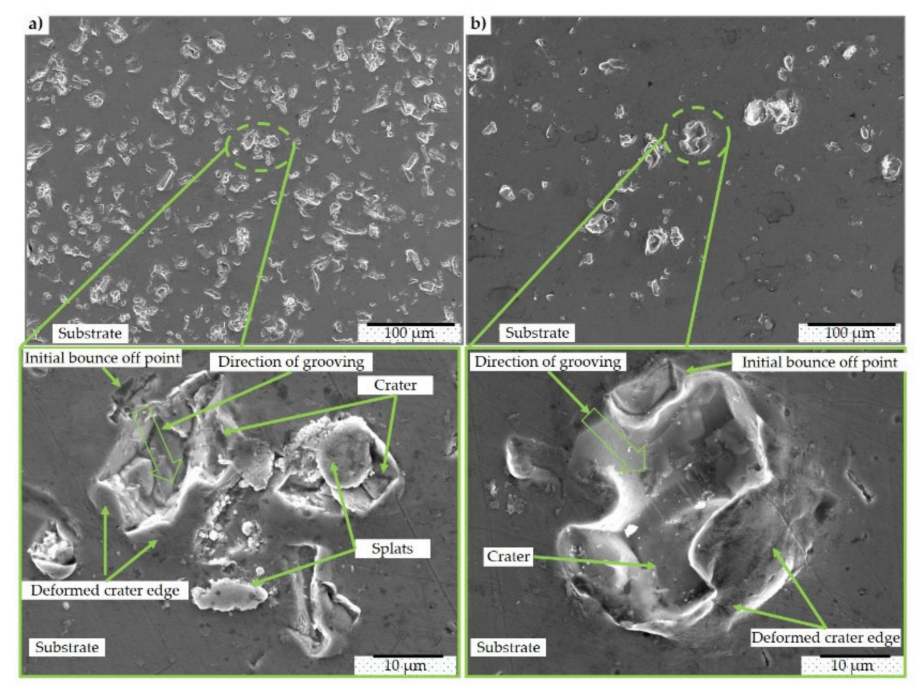

Figure 5. The effect of the size distribution of mixed in hard particles on the splat formation: (a) $\mathrm{Al}_{2} \mathrm{O}_{3}$ METCO $6103(-45+15 \mu \mathrm{m})$, (b) $\mathrm{Al}_{2} \mathrm{O}_{3}$ Amperit $740.002(-90+45 \mu \mathrm{m})$.

The size distribution of the hard particles has a higher impact on the splat formation. Even though all blended feedstock material has the same volume of hard particles, the number of hard particles in the case of $\mathrm{Al}_{2} \mathrm{O}_{3}$ METCO 6103 with the smaller size distribution is much higher compared with the other hard particle materials. The number of initiated craters is, therefore, much higher (compare Figure $5 a$ with Figure 5b), and the obtained splats are smaller. Furthermore, the initiated splats fit directly into these tiny craters, and thus benefit the interlocking of coating material with the deformed craters. The crater edges are subjected to severe deformation, which also indicates the deformation or (bounce off) direction of the impacting hard particles.

\subsection{Coating Development}

These findings strengthen the assumption made by Lee et al., in [17,18], that the in situ craters' development is the main factor for the coating formation. However, this assumption is limited only to the first layer (overrun) or if the coating and substrate material has the same hardness or is made from the same material. The increased number of craters leads to the activation of the surface layer and removing the surface impurities and oxide layers. An improvement of the coating interlocking with the substrate material is evident in the case of the smaller size distribution, as can be seen in Figure 6 . However, the coating thickness is about $25 \mu \mathrm{m}$ in the case of the smaller hard particles, which is about one-fifth of the coating thickness produced using coarser hard particles. The assumption is that the smaller hard particles have an erosion effect on the preceding layers, thus limiting the coating growth.

The coatings split up from the substrate by all other hard particles with the coarser hard particles. The splitting is solely owing to the preparation (cutting, grinding, and polishing) of the coating system for SEM analyses. Therefore, the embedding material was found between the coating and substrate (see Figure 6b). 

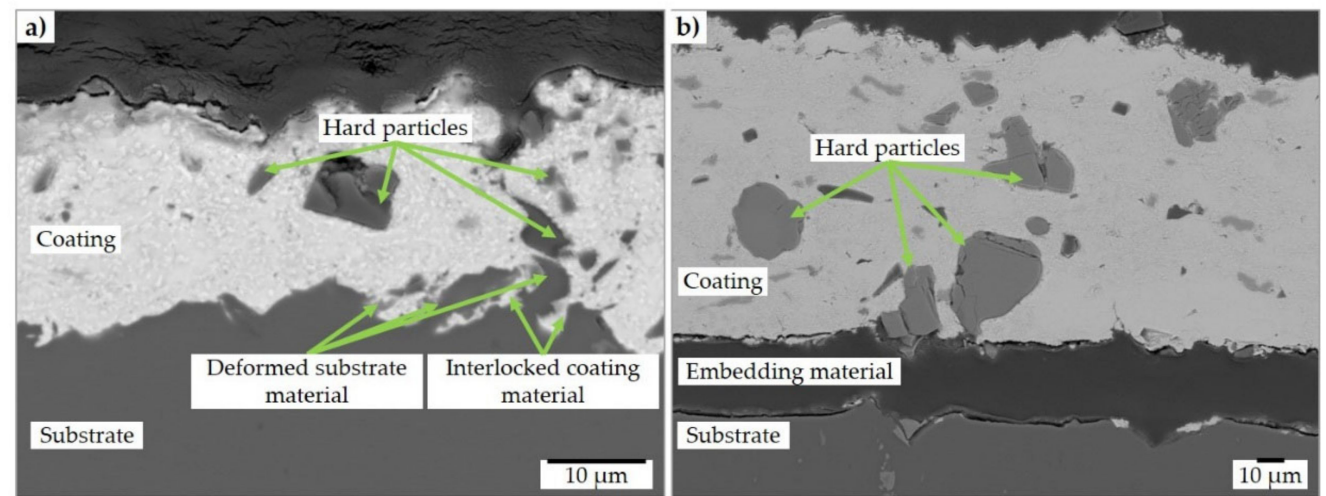

Figure 6. The interface between the substrate surface and the obtained coating: (a) coating produced using $\mathrm{Al}_{2} \mathrm{O}_{3}$ METCO $6103(-45+15 \mu \mathrm{m})$, (b) coating produced using $\mathrm{Al}_{2} \mathrm{O}_{3}$ Amperit $740.002(-90+45$ $\mu \mathrm{m})$.

The punches used to perform the coating adhesion tests show a clear penetration of the glue on the coated punches using $\mathrm{Al}_{2} \mathrm{O}_{3}$ mixed-in coarse powders, as shown in Figure 7, which indicates a spalling off effect of these coatings. This kind of effect is detrimental to the coating adhesion.

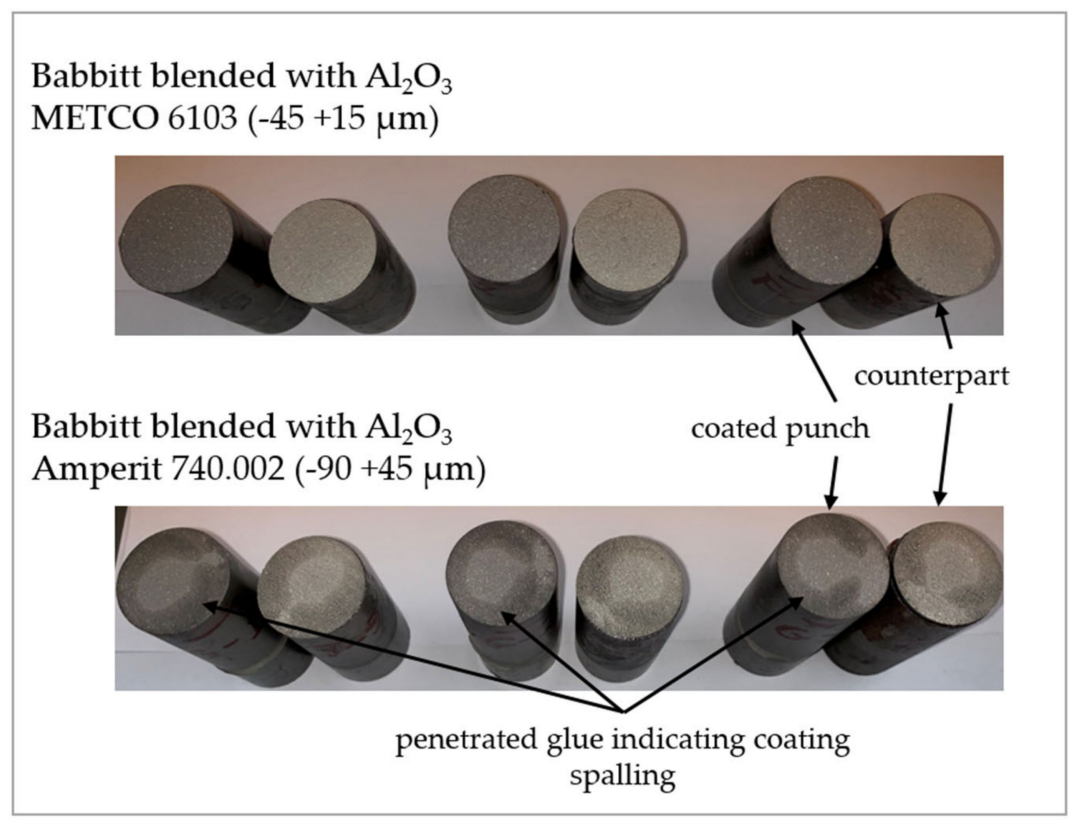

Figure 7. Coated punches and counterparts after the applied adhesion tests.

\subsection{Embedding of the Hard Particles}

The images in Figure 8. show that no metallic bond is formed between the coating and the hard particles. However, the hard particles are well embedded in the coating, and the images show no pullouts of hard particles from the coating through the preparation work. This finding is probably favored by the angular shape of the hard particles. The debris at the edges of the $\mathrm{B}_{4} \mathrm{C}$ hard particle is extremely likely due to its brittle impact behavior, which is caused by the impulse forces. 

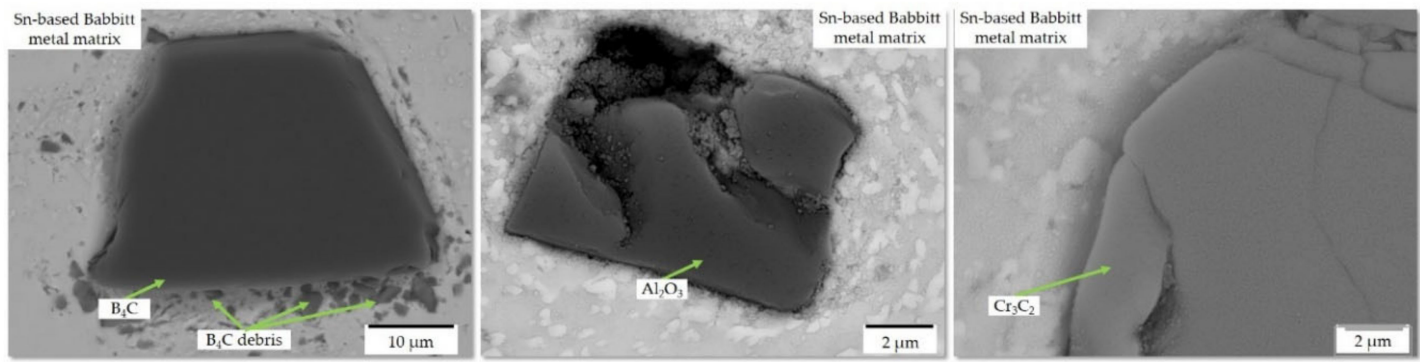

Figure 8. Embedding of hard particles in Sn-based Babbitt coating.

Figure 9 shows a line scan of the different embedded hard particles. Low diffusion is revealed for all hard particles, which is mainly owing to the low process temperatures in LPCGDS. However, in the case of $\mathrm{Cr}_{2} \mathrm{C}_{3}$, a higher diffusion is evident, as can be seen in Figure $9 \mathrm{~b}$.
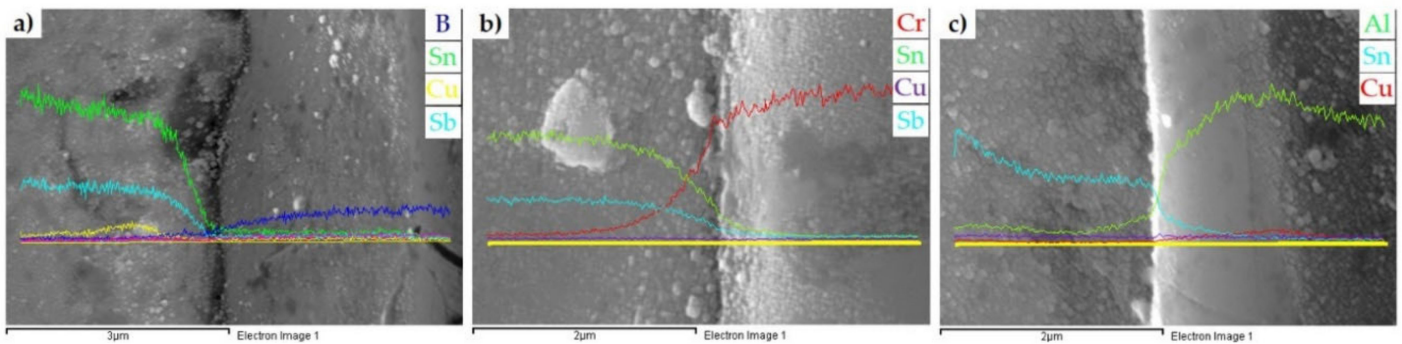

Figure 9. Line scan of the interface between Sb-based Babbitt metallic matrix: (a) $\mathrm{B}_{4} \mathrm{C} ;(\mathbf{b}) \mathrm{Cr}_{2} \mathrm{C}_{3}$, and (c) $\mathrm{Al}_{3} \mathrm{O}_{2}$.

\subsection{Friction and Wear Behavior}

It can be seen that all friction curves show a run-in phase with adhesive interactions, and thus an increased coefficient of friction, especially the combinations of Babbitt and $\mathrm{Cr}_{3} \mathrm{C}_{2}$. After the running-in phase, the friction behavior settles at almost a constant level for each of the combinations. Figure 10 further shows that the friction behavior of the individual combination is similar except for the combination with $\mathrm{B}_{4} \mathrm{C}$, where the friction coefficient remains constant for a while and starts to increase. One reason for the increase in the friction coefficient in the case of $\mathrm{B}_{4} \mathrm{C}$ could be the debris accumulation (see Figure 8). The friction values indicate that a similar friction curve can be observed, as in Ji et al. [22].

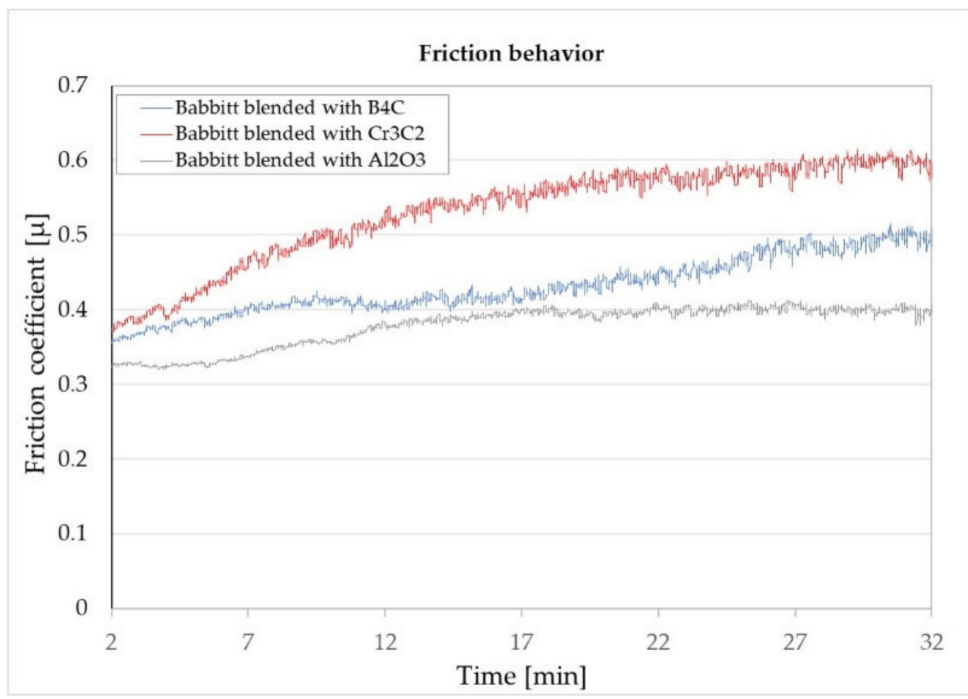

Figure 10. The coefficient of friction of the different Sn-based Babbitt coatings. 


\section{Conclusions}

The inclusion of micron-sized ceramic particles is a promising attempt to enhance the performance of LPCGDS obtained coatings. In this study, three different types of hard particles $\left(\mathrm{Al}_{2} \mathrm{O}_{3}, \mathrm{Cr}_{3} \mathrm{C}_{2}\right.$, and $\mathrm{B}_{4} \mathrm{C}$ ) with different material density and identical shapes were blended with Sn-based Babbitt Grade3. All three materials have the same powder size distribution as well as the same shape. In the case of $\mathrm{Al}_{2} \mathrm{O}_{3}$, two different types of powders with different size distribution were used to investigate the effect of the powder size on the coating development. All coatings showed excellent embedding behavior for all hard particles. The size distribution of the hard particles has a higher impact on splat formation and coating development. Smaller hard particles enhanced the interlocking between coating and substrate material. However, the same particles had a detrimental effect on the coating growth. Therefore, it will be beneficial to use the feedstock with smaller mixed in hard particles for the first layer to improve the coating adhesion and the feedstock with coarser ones for the successive layers. Furthermore, the investigation should be extended to include the effect of the shape of the hard particles, as well as the changing of the process parameter on the embedding and friction behavior of Sn-based Babbitt coatings.

Author Contributions: Conceptualization, M.A. and L.H.; methodology, M.A.; formal analysis, M.A. and S.H.; investigation, M.A.; resources, M.A. and L.H.; data curation, M.A.; writing-original draft preparation, M.A.; writing-review and editing, M.A. and W.T.; visualization, M.A. and S.H.; supervision, W.T.; project administration, M.A, and W.T. All authors have read and agreed to the published version of the manuscript.

Funding: The authors gratefully acknowledge the financial support by Deutsche Forschungsgemeinschaft and Technische Universität Dortmund/TU Dortmund Technical University within the funding programme Open Access Publishing.

Conflicts of Interest: The authors declare no conflict of interest.

\section{References}

1. Stewart, D.A.; Shipway, P.H. Abrasive wear behaviour of conventional and nanocomposite HVOF-sprayed WC-Co coatings. Wear 1999, 225, 789-798. [CrossRef]

2. Guilemany, J.M.; De Paco, J.M. Characterization of the $\mathrm{W}_{2} \mathrm{C}$ phase formed during the high velocity oxygen fuel spraying of a WC+12\%Co powder. Met. Mater. Trans. A 1999, 30, 1913-1921. [CrossRef]

3. Chivavibul, P.; Watanabe, M. Development of WC-Co coatings deposited by warm spray process. J. Spray Technol. 2008, 17, 750-756. [CrossRef]

4. Chivavibul, P.; Watanabe, M. Effects of particle strength of feedstock powders on properties of warm-sprayed WC-Co coatings. J. Spray Technol. 2011, 20, 1098-1109. [CrossRef]

5. Champagne, V. The Cold Spray Materials Deposition Process: Fundamentals and Application, 1st ed.; Woodhead Publishing: Boca Raton, FL, USA, 2007.

6. Vilardell, A.M.; Cinca, N. Feasibility of using low pressure cold gas spray for the spraying of thick ceramic hydroxyapatite coatings. Int. J. Appl. Ceram. Technol. 2019, 16, 221-229. [CrossRef]

7. Ganesan, A.; Affi, J. Bonding behavior studies of cold sprayed Copper coating on the PVC polymer substrate. Surf. Coat. Technol. 2012, 207, 262-269. [CrossRef]

8. Winnicki, M.; Małachowska, A.; Rutkowska-Gorczyca, M.; Sokołowski, P.; Ambroziak, A.; Pawłowski, L. Characterization of cermet coatings deposited by low-pressure cold spraying. Surf. Coat. Technol. 2015, 268, 108-114. [CrossRef]

9. Małachowska, A.; Winnicki, M.; Stachowicz, M.; Korzeniowski, M. Metallisation of polycarbonates using a low pressure cold spray method. Surf. Eng. 2018, 34, 251-258. [CrossRef]

10. Klinkov, S.V.; Kosarev, V.F. Cold spray deposition: Significance of particle impact phenomena. Aerosp. Sci. Technol. 2005, 9, 582-591. [CrossRef]

11. Yin, S.; Meyer, M. Gas flow, particle acceleration, and heat transfer in cold spray: A review. J. Spray Technol. 2016, 25, 874-896. [CrossRef]

12. Assadi, H.; Kreye, H. Cold spraying-A materials perspective. Acta Mater. 2016, 116, 382-407. [CrossRef]

13. Rokni, M.R.; Nutt, S.R. Review of relationship between particle deformation, coating microstructure, and properties in high-pressure cold spray. J. Spray Technol. 2017, 26, 1308-1355. [CrossRef] 
14. Luzin, V.; Spencer, K. Residual stress and thermo-mechanical properties of cold spray metal coatings. Acta Mater. 2011, 59, 1259-1270. [CrossRef]

15. Venkatesh, L.; Chavan, N.M. The influence of powder particle velocity and microstructure on the properties of cold sprayed Copper coatings. J. Spray Technol. 2011, 20, 1009-1021. [CrossRef]

16. Melendez, N.M.; McDonald, A.G. Development of WC-based metal matrix composite coatings using low-pressure cold gas dynamic spraying. Surf. Coat. Technol. 2013, 214, 101-109. [CrossRef]

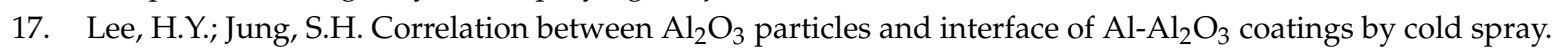
Appl. Surf. Sci. 2005, 252, 1891-1898. [CrossRef]

18. Lee, H.Y.; Yu, Y.H. Cold spray of $\mathrm{SiC}$ and $\mathrm{Al}_{2} \mathrm{O}_{3}$ with soft metal incorporation: A technical contribution. J. Spray Technol. 2004, 13, 184-189. [CrossRef]

19. Nascimento, A.R.C.; Ettouil, F.B. Production of Babbitt Coatings by High Velocity Oxygen Fuel (HVOF) Spraying. J. Spray Technol. 2017, 7, 1732-1740. [CrossRef]

20. Azizpour, M.J.; Majd, S.N.H.M. Babbitt Casting and Babbitt Spraying Processes Case Study. Int. J. Mech. Mechatron. Eng. 2011, 5, 1628-1630.

21. Zeren, A.; Feyzullahoglu, E. A study on tribological behaviour of Tin-based bearing material in dry sliding. Mater. Des. 2007, 1, 318-323. [CrossRef]

22. Ji, X.; Chen, Y. Tribological Behavior of Babbitt Alloy Rubbing Against Si3N4 and Steel Under Dry Friction Condition. J. Mater. Eng. Perform. 2016, 3, 750-755. [CrossRef]

(C) 2020 by the authors. Licensee MDPI, Basel, Switzerland. This article is an open access article distributed under the terms and conditions of the Creative Commons Attribution (CC BY) license (http://creativecommons.org/licenses/by/4.0/). 